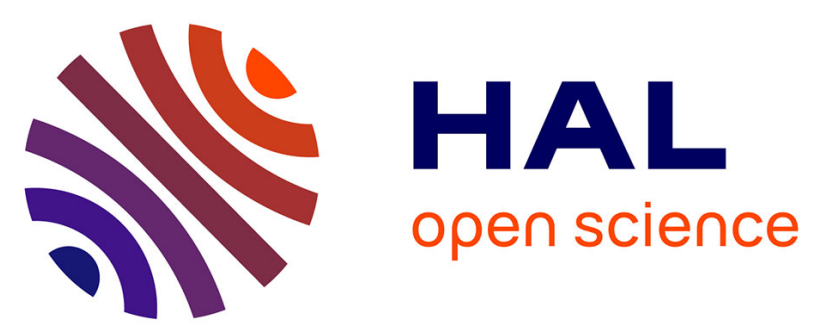

\title{
Efficacy of rifampin, in monotherapy and in combinations, in an experimental murine pneumonia model caused by panresistant strains
}

M. E. Pachón-Ibáñez, F. Docobo-Pérez, M. E. Jiménez-Mejias, J. Ibáñez-Martínez, A. García-Curiel, C. Pichardo, J. Pachón

\section{To cite this version:}

M. E. Pachón-Ibáñez, F. Docobo-Pérez, M. E. Jiménez-Mejias, J. Ibáñez-Martínez, A. García-Curiel, et al.. Efficacy of rifampin, in monotherapy and in combinations, in an experimental murine pneumonia model caused by panresistant strains. European Journal of Clinical Microbiology and Infectious Diseases, 2011, 30 (7), pp.895-901. 10.1007/s10096-011-1173-6 . hal-00671830

\section{HAL Id: hal-00671830 \\ https://hal.science/hal-00671830}

Submitted on 19 Feb 2012

HAL is a multi-disciplinary open access archive for the deposit and dissemination of scientific research documents, whether they are published or not. The documents may come from teaching and research institutions in France or abroad, or from public or private research centers.
L'archive ouverte pluridisciplinaire HAL, est destinée au dépôt et à la diffusion de documents scientifiques de niveau recherche, publiés ou non, émanant des établissements d'enseignement et de recherche français ou étrangers, des laboratoires publics ou privés. 
1 Efficacy of rifampin, in monotherapy and combination, in an experimental murine

2 pneumonia model caused by panresistant Acinetobacter baumannii strains

3

4

5 María Eugenia Pachón-Ibáñez PhD*\#, Fernando Docobo-Pérez PhD ${ }^{\#}$, Manuel 6 Enrique Jiménez-Mejias MD, PhD, José Ibáñez-Martínez MD, PhD, Andrés 7 García-Curiel MD, PhD, Cristina Pichardo MD, PhD, Jerónimo Pachón MD, PhD. 8

9 From the Infectious Diseases Services (MEPI, FDP, MEJM, CP, JP) and Service of 10 Microbiology (AGC), Institute of Biomedicine of Sevilla (IBIS), University Hospital 11 Virgen del Rocío/CSIC/University of Sevilla, Sevilla, Spain, and Department of 12 Pathology (JIM), University Hospital Virgen Macarena, Sevilla, Spain.

$15 *$ Corresponding author. Mailing address:

16 Dr. María Eugenia Pachón Ibáñez

17 Mailing address: Department of Immunology and Microbial Science. SP30-2110, The

18 Scripps Research Institute, 10550 North Torrey Pines Road, La Jolla, CA 92037, USA.

19 Phone: (858) 784 7079; E-mail: meniapi@ hotmail.com

20

21

$22{ }^{\#}$ MEPI and FDP contributed equally to the manuscript. 


\section{ABSTRACT}

25 The objective of this work was to evaluate the efficacy of rifampin, and its 26 combinations with imipenem or sulbactam, in an experimental pneumonia model caused

27 by two panresistant A. baumannii strains (HUVR99, HUVR113). MICs and MBCs $28(\mu \mathrm{g} / \mathrm{ml})$ of the strains were: rifampin 128/>128 for both strains, imipenem 128/>256 and $29256 />256$ for HUVR99 and HUVR113, respectively, and sulbactam >256/>256 for both 30 strains. In time-kill studies, at MIC concentrations, rifampin was bactericidal for both 31 strains and sulbactam against HUVR99 strain. Rifampin plus imipenem or sulbactam, at 32 MIC or mice $C_{\max }$, were synergistic. In vivo, against HUVR99 and HUVR113, rifampin 33 (73\% and 40\%) and its combinations improved the survival respect to the control group $34(20 \%$ and $0 \%, \mathrm{p}<0.05)$, respectively. Rifampin $(87 \%$ and $46 \%)$ and its combinations 35 improved the sterilization of blood cultures, respect to the control groups $(0 \%, \mathrm{p}<0.05)$. 36 In regard with the bacterial clearance from lungs, rifampin $(2.57 \pm 2.47$ and $5.35 \pm 3.03$ $37 \log _{10} \mathrm{cfu} / \mathrm{g}$ ) and its combinations with imipenem or sulbactam diminished the bacterial 38 lung concentration respect to the control group $(10.89 \pm 3.00$ and $11.86 \pm 0.49, \mathrm{p}<0.05)$ 39 with both strains. In conclusion, rifampin alone or associated to imipenem or sulbactam 40 were effective for the treatment of murine pneumonia caused by selected panresistant $A$. 41 baumannii strains.

43 Keywords: panresistant, Acinetobacter baumannii, experimental pneumonia model, 44 rifampin, sulbactam, imipenem. 


\section{INTRODUCTION}

48 Acinetobacter baumannii is an important nosocomial pathogen [1,2], particularly in

49 intensive care units settings. The treatment of these infections is challenged by the

50 ability of this microorganism to acquire resistance to almost all antibiotics, including

51 carbapenems $[3,4]$. In these situations, alternative options are scarce, and only colistin

52 and rifampin are active against these multidrug-resistant strains. Thus, colistin has been

53 restored for the treatment of severe multidrug-resistant A. baumannii infections [5-7],

54 although the mortality in infections as ventilator-associated pneumonia remains around

40\%. However, infections caused by colistin-resistant strains have been reported [8-11]

56 which have prompted to explore other alternative treatments for infections caused by

57 these strains.

58 Montero et al. [12], using an experimental murine pneumonia model caused by 59 carbapenem-resistant $A$. baumannii strains, found that the addition of colistin did not

60 improve the efficacy of rifampin alone; on the contrary imipenem plus rifampin was

61 more efficacious than rifampin's monotherapy. We also showed that rifampin was better

62 than colistin in reducing bacterial lung concentration in an experimental murine

63 pneumonia model caused by a carbapenem-resistant $A$. baumannii, and that the addition

64 of colistin to rifampin did not improve its efficacy; however, imipenem or sulbactam

65 plus rifampin decrease $1 \log _{10} \mathrm{cfu} / \mathrm{g}$ of lung compared with rifampin alone [13].

66 The aim of the present study was to evaluate the efficacy of rifampicin, associated to

67 imipenem or sulbactam, against clinical isolates of panresistant A. baumannii, including

68 resistance to colistin, using an experimental murine pneumonia model.

69 
71 Bacterial strains. We used two bacteraemic panresistant A. baumannii strains

72 (HUVR99 and HUVR113) belonging to the same clone responsible for an outbreak in

our hospital [8]. Isolates were identified as A. baumannii by means of Gram staining, observation of their colonial morphology and motility, use of cytochrome oxidase reaction analysis, determination of whether there was growth at $44^{\circ} \mathrm{C}$, as well as by the use of a semiautomated microbiology system (MicroScanWalk-Away; Dade-Behring). Additionally, the strains were confirmed as A. baumannii by the use of amplified ribosomal DNA restriction analysis [14].

Antibacterial agents and drugs. In the in vitro assays, antibacterial agents were used as laboratory standard powders: imipenem (Merck, Sharp \& Dohme, Madrid, Spain), sulbactam (PharmaSierra, Madrid, Spain), and rifampin and colistin sulfate (SigmaAldrich, Madrid, Spain). For the in vivo experiments, we used imipenem and sulbactam as commercial vials from the same manufacturers as above, and rifampin from Aventis (Madrid, Spain). Sodium thiopental (5\% wt/vol) was provided by B. Braun Medical S.A. (Barcelona, Spain).

Susceptibility testing and time-kill curve experiments. MICs and MBCs were determined according standard methods [15,16]. Escherichia coli ATCC 25922 was used as a control strain. The breakpoints for resistance were those defined by the Clinical and Laboratory Standards Institute [15], and the French Society for Microbiology for rifampin [16].

Time-kill kinetic assays were conducted on Mueller-Hinton broth (MHB) at drug concentrations of MIC and $C_{\max }$ (peak drug serum concentration in C57BL/6 female healthy mice, after a single dose of $30 \mathrm{mg} / \mathrm{kg}$ intramuscularly (i.m.) for imipenem, 60 
114 Drug pharmacokinetics. Serum drug levels were determined in groups of 21 healthy

115 mice after administration of a single dose of each antibacterial agent. The dosages 116 administered were: $30 \mathrm{mg} / \mathrm{kg} / \mathrm{i} . \mathrm{m}$. for imipenem, $60 \mathrm{mg} / \mathrm{kg} / \mathrm{i} . \mathrm{m}$. for sulbactam, and 25 $117 \mathrm{mg} / \mathrm{kg} /$ i.p. for rifampin. After 10, 15, 30, 60, 90, 120, and $150 \mathrm{~min}$, blood samples were 118 drawn from the periorbital plexus of three anesthetized mice per time-point. Drug 119 concentrations were measured by a bioassay method, using Micrococcus luteus ATCC

$\mathrm{mg} / \mathrm{kg}$ i.m. for sulbactam, and $25 \mathrm{mg} / \mathrm{kg}$ intraperitoneally (i.p.) for rifampin. A control without antibiotics was evaluated in parallel. The initial inoculum was approximately $10^{5} \mathrm{cfu} / \mathrm{ml}$. Cultures were incubated at $37^{\circ} \mathrm{C}$ and bacterial counts were determined by plating $100 \mu \mathrm{l}$ of ten-fold dilutions of control or test tubes, onto sheep blood agar plates (SBA), at $0,2,4,8$, and $24 \mathrm{~h}$. Plates were incubated for $24 \mathrm{~h}$ at $37^{\circ} \mathrm{C}$. Bactericidal activity was defined as $\geq 3 \log _{10}$ decrease of the initial inoculum in cfu/ml [17].

In vitro synergies of rifampin plus imipenem or sulbactam against the two strains were tested with time-kill assays. Concentrations of MIC or $C_{\max }$ of each antibacterial agent were used. Synergy was defined as $\geq 2 \log _{10}$ decreases in bacterial concentration, in comparison with the most active drug alone [18].

The in vitro experiments were performed in duplicate. Moreover, MIC and MBC were repeated periodically to check that the susceptibilities of both strains did not change during the in vivo experiments.

Animals. Immunocompetent C57BL/6 female mice, weighing 16 to $20 \mathrm{~g}$, obtained from the University of Sevilla's facility were used. The in vivo studies were approved by the Ethics Committee of the Hospital Universitario Virgen del Rocío, Sevilla, Spain. 9341, Bacillus subtilis 6633, and A. baumannii ATCC 19606 as control strains [19]. 
121 Maximum plasma concentration $\left(C_{\max }, \mu \mathrm{g} / \mathrm{ml}\right)$, terminal half-life $\left(t_{1 / 2}\right.$, hours), and AUC

$122(\mu \mathrm{g} / \mathrm{h} / \mathrm{ml})$ were calculated by a computer-assisted method

123 (http://www.boomer.org/pkin/soft.html). The time during which the plasma

124 concentration remained above the MIC ( $\Delta \mathrm{T} / \mathrm{MIC}$, hours) was estimated by extrapolation

125 from the regression line of plasma elimination.

126

127 Experimental pneumonia model in mice. A murine experimental pneumonia model 128 was carried out using A. baumannii HUVR99 and HUVR113 strains [20]. Anesthetized

129 animals were infected transtracheally with a final inoculum of approximately $10^{8} \mathrm{cfu} / \mathrm{ml}$

130 in $50 \mu \mathrm{l}$ of the bacterial suspension mixed 1:1 with porcine mucin (Sigma-Aldrich)

131 diluted to $10 \%$ in saline.

132

133 Antibacterial treatment. Mice were randomly ascribed into four treatment groups, for 72

134 h: control (non-treated), rifampin (100 mg/kg/day/i.p., q.i.d.), rifampin plus imipenem (120

$135 \mathrm{mg} / \mathrm{Kg} /$ day/i.m., q.i.d.), and rifampin plus sulbactam (240 mg/Kg/day/i.m., q.i.d.).

136 Because the strains used in these experiments were resistant to antibacterial agents, the

137 dosages were those showing efficacy in an experimental pneumonia model caused by 138 multidrug-resistant A. baumannii [13]. These dosages obtained, for imipenem and

139 sulbactam, plasma concentrations in the ranges of those reached in humans after standard

140 dosing for severe infections [21]. For rifampin, the dosage obtains an AUC similar to that

141 found in humans [22].

142 Therapy was initiated $4 \mathrm{~h}$ after the bacterial challenge, when histological features of 143 pneumonia appeared [20]. Animals were observed for $72 \mathrm{~h}$ for mortality, and surviving

144 mice were sacrificed $4 \mathrm{~h}$ after the last antibacterial agent dose by the administration of 145 sodium thiopental; all the mice were analyzed immediately after death. Thoracotomy 
146 was carried out and $100 \mu 1$ of blood, collected by cardiac puncture, was cultured in TSB

147 for $24 \mathrm{~h}$ at $37^{\circ} \mathrm{C}$ and then $100 \mu \mathrm{l}$ was plated on SBA plates and incubated for another 24

$148 \mathrm{~h}$ at $37^{\circ} \mathrm{C}$; results were expressed as positive or negative. Heart and lungs were

149 extracted in block and lungs were separated onto a sterile Petri plate, weighed, and

150 processed for quantitative culture after being homogenized (Stomacher 80 Tekmar Co.,

151 Cincinnati, Ohio, USA) in $2 \mathrm{ml}$ of sterile saline solution. After 10-fold dilution, aliquots

152 of $100 \mu \mathrm{l}$ were plated onto SBA plates for $24 \mathrm{~h}$ at $37^{\circ} \mathrm{C}$. If cultures were negative, lungs

153 were considered sterile, when no growth was observed after plating the whole residue of

154 the homogenized tissue onto SBA plates. Results were expressed as means \pm standard

155 deviations of the $\log _{10} \mathrm{cfu} / \mathrm{g}$ of lung.

156 Lung samples were processed for pathological studies in five mice from each control

157 group. Lungs were fixed with $10 \%$ formaldehyde and embedded in paraffin and cut into

$1584 \mu \mathrm{m}$ thick sections. The slices included all the pulmonary lobes to be studied by optical

159 microscopy. They were processed according to standard methods for hematoxylin-

160 eosin, periodic acid-Schiff, Gram, Masson's trichromic, and silver reticulin stains.

161 To confirm that the antibacterial treatments were not toxic to the animals, groups of 5

162 randomly non-infected mice were each given the antibiotics for $72 \mathrm{~h}$.

163

164 Statistical analysis. Therapeutic efficacy in each experiment was assessed comparing

165 the lung bacterial counts and the percentages of bacteremia and mortality among the

166 groups. Numbers of surviving animals and negative blood cultures were evaluated with

167 the Fisher's exact test. The cfu/g of lung tissue was analyzed using the homogeneity of

168 variance (ANOVA) and posthoc tests (Tukey-Kramer and Dunnet test). The SPSS 14.0

169 statistical package (SPSS Inc., Chicago, IL) was used. A $P$ value of 0.05 was considered

170 significant. 


\section{RESULTS}

173 In vitro studies. MIC and MBC of imipenem, sulbactam, rifampin, and colistin for $A$.

174 baumannii HUVR99 and HUVR113 are shown in Table 1.

175 For the time-kill experiments (Fig. 1 and 2) MIC $>256 \mu \mathrm{g} / \mathrm{ml}$ were fixed at $256 \mu \mathrm{g} / \mathrm{ml}$.

176 Against HUVR99 sulbactam was bactericidal at MIC at $8 \mathrm{~h}$ and at a concentration of

$177 C_{\max }$ at $24 \mathrm{~h}$, and rifampin at MIC at 4 and $8 \mathrm{~h}$; against HUVR113 only rifampin at MIC

178 was bactericidal at $4 \mathrm{~h}$. For both strains, synergy was found with rifampin plus

179 imipenem at both concentrations, MIC and $C_{\max }$. Rifampin plus sulbactam was

180 synergistic at MIC for HUVR99 and at MIC and $C_{\max }$ for HUVR113.

181

182 Pharmacokinetic studies. The pharmacokinetic and pharmacodynamic parameters of

183 each antibacterial agent are shown in Table 2. The $\Delta \mathrm{T} / \mathrm{MIC}$ for all the antibacterial 184 agents was 0 hours for both strains.

185

186 Pathological studies. The mice groups inoculated with strains HUVR99 and HUVR113

187 showed alterations compatible with acute pneumonia. They presented acute

188 inflammation, characterized by diffuse and/or focal affectation of all lobes, with a mild

189 to severe inflammatory infiltration of polymorphonuclear cells (PMN), sometimes

190 forming segmentary abscesses, and with mild to moderate infiltration of alveolar

191 macrophages. Gram-negative bacterial colonies and alveolar hemorrhagic areas were 192 also observed.

193

194 Therapeutic efficacy in experimental pneumonia. In vivo efficacy of the antibacterial

195 agents against both $A$. baumannii strains is shown in Table 3 . Survival rates in the 
196 control groups were 20\% and 0\% for strains HUVR99 and HUVR113, respectively. For

197 both, all the treatments improved survival rates compared with their controls $(P<0.05)$,

198 with no difference among the different treatments. In the sterilization of blood cultures,

199 for the strain HUVR99 all the treatments were efficacious $(P<0.05)$ compared with the

200 control group, with no difference among the antibacterial agents. For the strain

201 HUVR113 only rifampin and its combination with sulbactam increased the number of

202 sterile blood cultures ( $46 \%$ and $93.3 \%$ versus $0 \%$, respectively); moreover, rifampin

203 plus sulbactam was better than the other treatments $(93.3 \%$ versus $46 \%$ and $21 \%, P<$

204 0.05). Against both A. baumannii strains, HUVR99 and HUVR113, all treatment groups

205 decreased the lung bacterial counts when compared with the controls $(P<0.05)$. While

206 for strain HUVR99 there was no differences in lung clearance among the treatment

207 groups, against the HUVR113 rifampin plus sulbactam produced higher lung clearance

208 than that obtained with rifampin alone or combined with imipenem $(2.33 \pm 1.43$ versus

$2095.35 \pm 3.03$ and $6.80 \pm 2.19$, respectively $[P<0.05])$.

210 No toxicity was observed in the non-infected mice with the different therapies given

211 during $72 \mathrm{~h}$.

212

\section{DISCUSSION}

214 The present study shows that rifampin and its combinations with imipenem or

215 sulbactam are efficacious in the experimental pneumonia model caused by two $A$.

216 baumannii panresistant strains, in terms of diminished mortality and clearance of

217 bacteria from blood and lung tissue. In general, rifampin alone showed the same

218 efficacy that their combinations, but rifampin plus sulbactam were better than the

219 monotherapy with rifampin in the clearance of bacteria from blood and lung against one 
220 of the strains. These results are in accordance with the synergistic effect found in the

221 time-kill studies with this combination.

222 This therapeutic efficacy of rifampin agrees with the results found in several 223 experimental murine pneumonia models, using multiresistant A. baumannii strains. 224 Wolff et al. in a pneumonia model in neutropenic mice caused by using two $A$. 225 baumannii strains with different susceptibilities to rifampin [23], 8 and $4 \mu \mathrm{g} / \mathrm{ml}$ 226 respectively, observed improved survival and decrease in bacterial lung concentration 227 with rifampin. Montero et al. in an immunocompetent murine pneumonia model [12], 228 reported similar results with three A. baumannii strains with MIC of rifampin of 8 $229 \mu \mathrm{g} / \mathrm{ml}$. We also observed [13], in two experimental animal models of pneumonia in 230 immunocompetent mice and meningitis in rabbits, using an imipenen-resistant $A$. 231 baumannii strain with a MIC of rifampin of $4 \mu \mathrm{g} / \mathrm{ml}$, the therapeutic efficacy of this antibacterial agent alone and in combination, also in terms of improved survival and decrease of bacterial lung concentration.

234 Saballs et al. treated 10 patients with A. baumannii infections with rifampin plus 235 imipenem [24], curing eight cases in spite of the development of resistance to rifampin 236 in seven cases caused by strains with MIC of imipenem of $>256,128$, and $64 \mu \mathrm{g} / \mathrm{ml}$ in 2375,1 , and 1 , respectively.

238 The mechanisms by which rifampin was active in the experimental pneumonia caused 239 by highly-rifampin-resistant $A$. baumannii remains to be elucidated. The first may be 240 the synergistic in vitro effect of the two combinations, rifampin plus imipenem or 241 sulbactam, avoiding the regrowth of $A$. baumannii at 24 hours at $C_{\max }$, except in the case 242 of imipenem in the HUVR99 strain, suggesting the usefulness of these combinations for 243 the treatment of infections by panresistant A. baumannii. Other possibilities deserved 244 posterior studies. 
245 Some antibacterial agents, such as macrolides (clarithromycin or erythromycin), 246 azalydes (azithromycin) and ketolides (telithromycin), present higher levels at the 247 infection site, than that found in plasma [25], due to the accumulation in PMN or 248 epithelial linning fluid. Fluoroquinolones, such as ciprofloxacin, also present much 249 higher concentrations in the lung tissue than in plasma [26]. Respect to rifampin, 250 previous studies have shown accumulation inside PMN cells [27] or in alveolar macrophages, reaching 16.26 times the plasmatic concentration $(251.8$ and $15.1 \mu \mathrm{g} / \mathrm{ml}$, respectively) [28]. These accumulations could explain the effectiveness of rifampin in the treatment of pulmonary infections. In this way, the effectiveness of rifampin in the experimental pneumonia model by panresistant $A$. baumannii strains may be due to an accumulation of the drug in the alveolar macrophages, sufficient to eradicate the infection caused by this pathogen, or its transport to the infection site by PMN cells. The conditions in which a drug interacts with a pathogen in vivo are different to those in which the studies are carried out in vitro. Thus, the $\mathrm{pH}$ of the lung, infection site in the experimental model of $A$. baumannii of the present study, has an acid $\mathrm{pH}$ opposed to the

260 neutral $\mathrm{pH}$ of the medium in which the MIC is determined. This lower $\mathrm{pH}$ alters the 261 effectiveness of the antibacterial agents [29]. Therefore, one hypothesis is that the 262 acidity of $\mathrm{pH}$ of the lung could increase the susceptibility of the A. baumannii to 263 rifampin.

264 Rifampin has two major active metabolites, 25-O-deacetylrifampin produced by 265 deacetylation at hepatic level, and 3-formylrifamycin SV produced by hydrolysis at acid $266 \mathrm{pH}$. Both are detectable in serum and urine [30, 31]. It may be that the A. baumannii 267 strains, used in this study, display a greater susceptibility to these metabolites than to 268 rifampin. This could explain why the rifampin is more active against A. baumannii in 
269 vivo that in vitro, since in this last situation the metabolites derivates from rifampin

270 would not be generated.

271 In summary, the results of the present study suggest that rifampin and its combinations

272 with imipenem or sulbactam may be efficacious in the treatment of pulmonary

273 infections caused by panresistant strains of A. baumannii. However, because the high

274 MIC of rifampin against the A. baumannii strains used in this study, the mechanisms of

275 this in vivo experimental efficacy of rifampin must be elucidated, before the evaluation

276 of this therapy in humans.

277

278 


\section{ACKNOWLEDGMENTS}

280 This work was supported by research grants from the Consejería de Salud de la Junta de 281 Andalucía (13/02) and the Ministerio de Ciencia e Innovación, Instituto de Salud Carlos

282 III - co-financed by European Development Regional Fund "A way to achieve Europe" 283 ERDF, Spanish Network for the Research in Infectious Diseases (REIPI 284 RD06/0008/0000).

285 The results of this manuscript were presented in the $15^{\text {th }}$ ECCMID, Copenhagen, 286 Denmark, 2005.

287 


\section{REFERENCES}

1. Rodríguez-Baño J, Cisneros JM, Fernández-Cuenca F et al (2004) Clinical features and epidemiology of Acinetobacter baumannii colonization and infection in Spanish hospitals. Grupo de Estudio de Infección Hospitalaria (GEIH). Infect Control Hosp Epidemiol 25:819-824.

2. Rodríguez-Baño J, García L, Ramírez E et al (2009) Long-term control of hospital-wide, endemic multidrug-resistant Acinetobacter baumannii through a comprehensive "bundle" approach. Am J Infect Control 37:715-722.

3. Michalopoulos A, Falagas ME (2010) Treatment of Acinetobacter infections. Expert Opin Pharmacother 11:779-788.

4. McGowan JE Jr (2006) Resistance in nonfermenting gram-negative bacteria: multidrug resistance to the maximum. Am J Infect Control 34 (Suppl 1):S29-37; discussion S64-73.

5. Falagas ME, Kasiakou SK, Tsiodras $S$ et al (2006) The use of intravenous and aerosolized polymyxins for the treatment of infections in critically ill patients: a review of the recent literature. Clin Med Res 4:138-146.

6. Garnacho-Montero J, Ortiz-Leyba C, Jiménez-Jiménez FJ et al (2003) Treatment of multidrug-resistant Acinetobacter baumannii ventilator-associated pneumonia (VAP) with intravenous colistin: a comparison with imipenem-susceptible VAP. Clin Infect Dis 36:1111-1118.

7. De Pascale G, Pompucci A, Maviglia R, Spanu T, Bello G, Mangiola A et al (2010) Successful treatment of multidrug-resistant Acinetobacter baumannii ventriculitis with intrathecal and intravenous colistin. Minerva Anestesiol. May 6. [Epub ahead of print]. 
8. Valencia R, Arroyo LA, Conde M et al (2009) Nosocomial outbreak of infection with pan-drug-resistant Acinetobacter baumannii in a tertiary care university hospital. Infect Control Hosp Epidemiol 30:257-263.

9. Cisneros-Herreros JM, Garnacho-Montero J, Pachón-Ibáñez ME (2005) Nosocomial pneumonia due to Acinetobacter baumannii. Enferm Infecc Microbiol Clin 23 (Suppl 3):46-51.

10. Li J, L Nation R, Owen RJ, Wong S, Spelman D, Franklin C (2007) Antibiograms of multidrug-resistant clinical Acinetobacter baumannii: Antimicrob Chemother 60:1163-1167.

12. Montero A, Ariza J, Corbella X, et al (2004) Antibiotic combinations for serious infections caused by carbapenem-resistant Acinetobacter baumannii in a mouse pneumonia model. J Antimicrob Chemother 54:1085-1091.

13. Pachón-Ibáñez ME, Docobo-Pérez F, López-Rojas R, et al (2010) Efficacy of rifampin and its combinations with imipenem, sulbactam, and colistin in experimental models of infection caused by imipenem-resistant Acinetobacter baumannii. Antimicrob Agents Chemother 54:1165-1172.

14. Vaneechoutte M, Dijkshoorn L, Tjernberg I, et al (1995). Identification of Acinetobacter genomic species by amplified ribosomal DNA restriction analysis. J Clin Microbiol 33:11-15. 
15. Clinical and Laboratory Standards Institute (2010) Performance standards for antimicrobial susceptibility testing; Twentieth informational supplement. Document M100-S20. Clinical and Laboratory Standards Institute, Wayne, Pa.

16. Société Française de Microbiologie (2010) Comite de l'antibiogramme de la Société Française de Microbiologie, SFM, Paris. (www.sfm.asso.fr, accessed August 11, 2010).

17. National Committee for Clinical Laboratory Standards (1999) Methods for Determining Bactericidal Activity of Antimicrobial Agents: Approved Standard M26-A. NCCLS, Wayne, PA, USA.

18. Pillai SK, Moellering RC Jr, Eliopoulos GM (2005) Antimicrobial combinations. In: Lorian V, ed. Antibiotics in Laboratory Medicine. 5th ed. Philadelphia: Lippincott Williams \& Wilkins, pp 365-440.

19. Klein RD, Edberg SC (2005) Applications, significance of, and methods for the ed. Antibiotics in Laboratory Medicine. 5th ed. Philadelphia: Lippincott Williams \& Wilkins, pp 290-364.

20. Rodríguez-Hernández MJ, Pachón J, Pichardo C, et al (2000) Imipenem, doxycycline and amikacin in monotherapy and in combination in Acinetobacter baumannii experimental pneumonia. J Antimicrob Chemother 45:493-501.

21. Amsden GW (2010) Tables of antimicrobial agent pharmacology. In: Mandell GL, Bennett JE, and Dolin R, eds. Principles and practice of infectious diseases. 7th ed. Philadelphia: Churchill Livingstone Elsevier, pp 705-761.

22. Ruslami R, Nijland HM, Alisjahbana B, Parwati I, van Crevel R, Aarnoutse RE (2007) Pharmacokinetics and tolerability of a higher rifampin dose versus the 
standard dose in pulmonary tuberculosis patients. Antimicrob Agents Chemother 51: 2546-2551.

362

23. Wolff M, Joly-Guillou ML, Farinotti R, Carbon C (1999) In vivo efficacies of combinations of beta-lactams, beta-lactamase inhibitors, and rifampin against Acinetobacter baumannii in a mouse pneumonia model. Antimicrob Agents Chemother 43:1406-1411.

24. Saballs M, Pujol M, Tubau F, et al (2006) Rifampicin/imipenem combination in the treatment of carbapenem-resistant Acinetobacter baumannii infections. J Antimicrob Chemother 58:697-700.

25. Drusano GL (2005) Infection site concentrations: Their importance and the macrolide and macrolide-like class of antibiotics. Pharmacotherapy 25:150S$158 \mathrm{~S}$.

26. Bamberger DM, Foxworth JW, Bridwell DL, Shain CS, Gerding DN (2005) Extravascular antimicrobial distribution and the respective blood and urine concentrations in humans. In: Lorian V, ed. Antibiotics in Laboratory Medicine. 5th ed. Philadelphia: Lippincott Williams \& Wilkins, pp 719-814.

27. Prokesch RC, Hand LW (1982) Antibiotic entry into human Polymorphonuclear leukocytes. Antimicrob Agents Chemother 21:373-380.

28. Ziglam HM, Baldwin DR, Daniels I, Andrew JM, Finch RG (2002) Rifampicin concentrations in bronchial mucosa, epithelial lining fluid, alveolar macrophages and serum following a single $600 \mathrm{mg}$ oral dose in patients undergoing fibreoptic bronchoscopy. J Antimicrob Chemother 50:1011-1015.

29. Barcia-Macay M, Seral C, Mingeot-Leclercq MP, Tulkens PM, Van Bambeke F (2006) Pharmacodynamic evaluation of intracellular activities of antibiotics 
against Staphylococcus aureus in a model of THP-1 macrophages. Antimicrob Agents Chemother 50:841-851.

30. Inderlied CB, Nash KA (2005) Antimycobacterial agents: In vitro susceptibility testing and mechanism of action and resistance. In: Lorian V, ed. Antibiotics in Laboratory Medicine. Philadelphia: Lippincott Williams \& Wilkins, pp 155-225.

31. Weber A, Opheim KE, Smith AL, Wong K (1983) High-pressure liquid chromatographic quantitation of rifampin and its two major metabolites in urine and serum. Rev Infect Dis 5:S433-S439.

392

393 
394 Table 1. MIC and MBC of imipenem, sulbactam, rifampin, and colistin for HUVR99

395 and HUVR113 A. baumannii panresistant strains.

\begin{tabular}{lcc}
\hline Antibacterial & \multicolumn{2}{c}{ MIC / MBC $(\boldsymbol{\mu g} / \mathbf{m l})$} \\
\cline { 2 - 3 } agents & Strain HUVR99 & Strain HUVR113 \\
\hline Imipenem & $128 />256$ & $>256 />256$ \\
Sulbactam & $>256 />256$ & $>256 />256$ \\
Rifampin & $128 />128$ & $128 />128$ \\
Colistin & $32 />32$ & $32 />32$ \\
\hline
\end{tabular}

396

397 MIC: minimal inhibitory concentration

398 MBC: minimal bactericidal concentration

399 
400 Table 2. Pharmacokinetic and pharmacodynamic parameters of imipenem, sulbactam, 401 and rifampin in mice.

402

\begin{tabular}{|c|c|c|c|c|c|}
\hline $\begin{array}{l}\text { Antimibacterial } \\
\text { agents (dose) }\end{array}$ & $\begin{array}{c}C_{\max } \\
(\mu \mathrm{g} / \mathrm{ml})\end{array}$ & $\begin{array}{l}t_{1 / 2} \\
(h)\end{array}$ & $\begin{array}{c}A \mathrm{UC}_{0-\mathrm{t}} \\
(\boldsymbol{\mu g} \cdot \mathbf{h} / \mathrm{ml})\end{array}$ & $C \max / \mathrm{MIC}$ & $\mathrm{AUC}_{0-24 \mathrm{~h}} / \mathrm{MIC}$ \\
\hline Imipenem (30 mg/kg) & 23.25 & 0.26 & 11.29 & $\begin{array}{l}0.18^{\mathrm{a}} \\
0.09^{\mathrm{b}}\end{array}$ & $\begin{array}{l}0.35^{\mathrm{a}} \\
0.18^{\mathrm{b}}\end{array}$ \\
\hline Sulbactam $(60 \mathrm{mg} / \mathrm{kg})$ & 89.45 & 0.35 & 87.51 & $0.35^{\mathrm{a}, \mathrm{b}}$ & $1.36^{\mathrm{a}, \mathrm{b}}$ \\
\hline Rifampin (25 mg/kg) & 15.75 & 2.86 & 24.76 & $0.12^{\mathrm{a}, \mathrm{b}}$ & $0.77^{\mathrm{a}, \mathrm{b}}$ \\
\hline
\end{tabular}

$403{ }^{\mathrm{a}}$ Parameter calculated for the strain HUVR99.

$404{ }^{\mathrm{b}}$ Parameter calculated for the strain HUVR113.

$405 C_{\max }$ : The maximum plasma concentration; $t_{1 / 2}$ : terminal half-life; $\mathrm{AUC}_{0-\mathrm{t}}:$ area under

406 the concentration-time curve; $C_{\max } / \mathrm{MIC}$, peak concentration above the $\mathrm{MIC} ; \mathrm{AUC}_{0-24 \mathrm{~h}} /$

407 MIC, area under the concentration-time curve above the MIC (256 $\mu \mathrm{g} / \mathrm{ml}$ for sulbactam

408 in both strains and imipenem in the strain HUVR113).

409 
410 Table 3. In vivo therapeutic efficacy of rifampin (RIF), imipenem (IPM), sulbactam

411 (SB) and its combinations in the experimental pneumonia by A. baumannii HUVR99

412 and HUVR113.

413

\section{A. baumannii HUVR99}

\section{A. baumannii HUVR113}

\begin{tabular}{lcccccccc} 
Treatment & & Survival & Sterile blood & Log cfu/g of & & Survival & Sterile blood & Log cfu/g of \\
& $\mathbf{n}$ & $(\%)$ & cultures $(\%)$ & lung \pm S.D. & $(\%)$ & cultures (\%) & lung \pm S.D. \\
\hline Control & 14 & $2(20)$ & $0(0)$ & $10.89 \pm 3.00$ & 15 & $0(0)$ & $0(0)$ & $11.86 \pm 0.49$ \\
RIF & 15 & $11(73)^{a}$ & $13(87)^{a}$ & $2.57 \pm 2.47^{a}$ & 15 & $6(40)^{a}$ & $7(46)^{a}$ & $5.35 \pm 3.03^{a}$ \\
RIF + IPM & 15 & $12(80)^{a}$ & $13(87)^{a}$ & $2.62 \pm 1.74^{a}$ & 15 & $5(33)^{a}$ & $3(21)$ & $6.80 \pm 2.19^{a}$ \\
RIF + SB & 14 & $8(60)^{a}$ & $10(71.4)^{a}$ & $2.53 \pm 2.28^{a}$ & 15 & $8(53)^{a}$ & $14(93.3)^{a, b}$ & $2.33 \pm 1.43^{a, b}$
\end{tabular}

414

$415{ }^{a} P<0.05$ compared with the control group.

$416{ }^{b} P<0.05$ compared to the other treatment groups.

417 
418 Fig 1. Time-kill assays of rifampin, imipenem, sulbactam, and the combinations of

419 rifampin plus imipenem or sulbactam against A. baumannii HUVR99 at MIC and serum 420 mice $C_{\max }$.

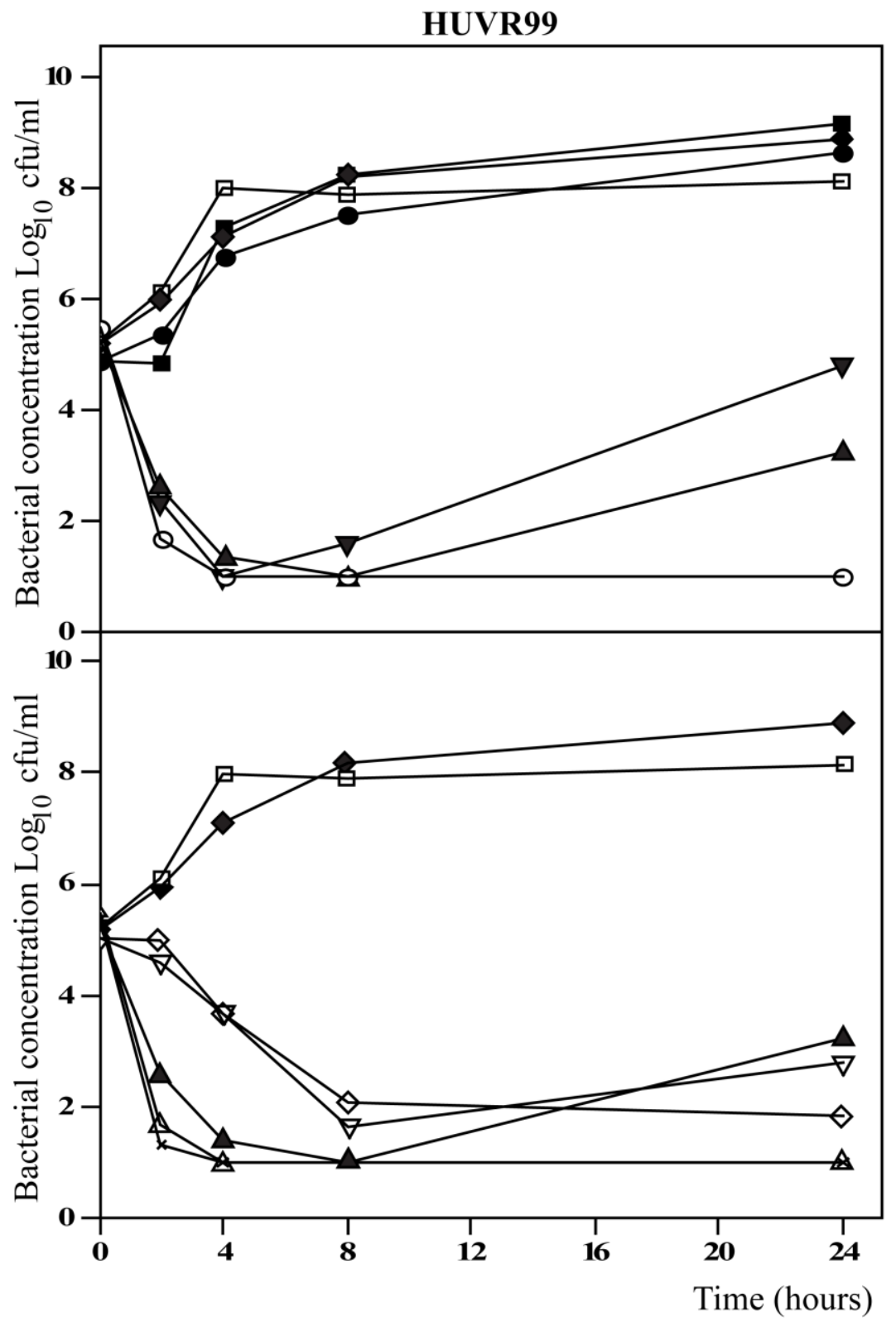

Figure 1, legend. Control, filled diamond; rifampin (MIC), filled triangle; rifampin $\left(C_{\max }\right)$, 423 open square; imipenem (MIC), filled square; imipenem $\left(C_{\max }\right)$, filled circle; sulbactam 424 (MIC) open inverted triangle; sulbactam $\left(C_{\max }\right)$, open diamond; rifampin plus imipenem 425 (MIC), open circle; rifampin plus imipenem $\left(C_{\max }\right)$, inverted filled triangle; rifampin plus 426 sulbactam (MIC), open triangle; rifampin plus sulbactam $\left(C_{\max }\right)$, black cross. 
428 Fig 2. Time-kill assays of rifampin, imipenem, sulbactam, and the combinations of

429 rifampin plus imipenem or sulbactam against $A$. baumannii HUVR113 at MIC and serum 430 mice $C_{\max }$.

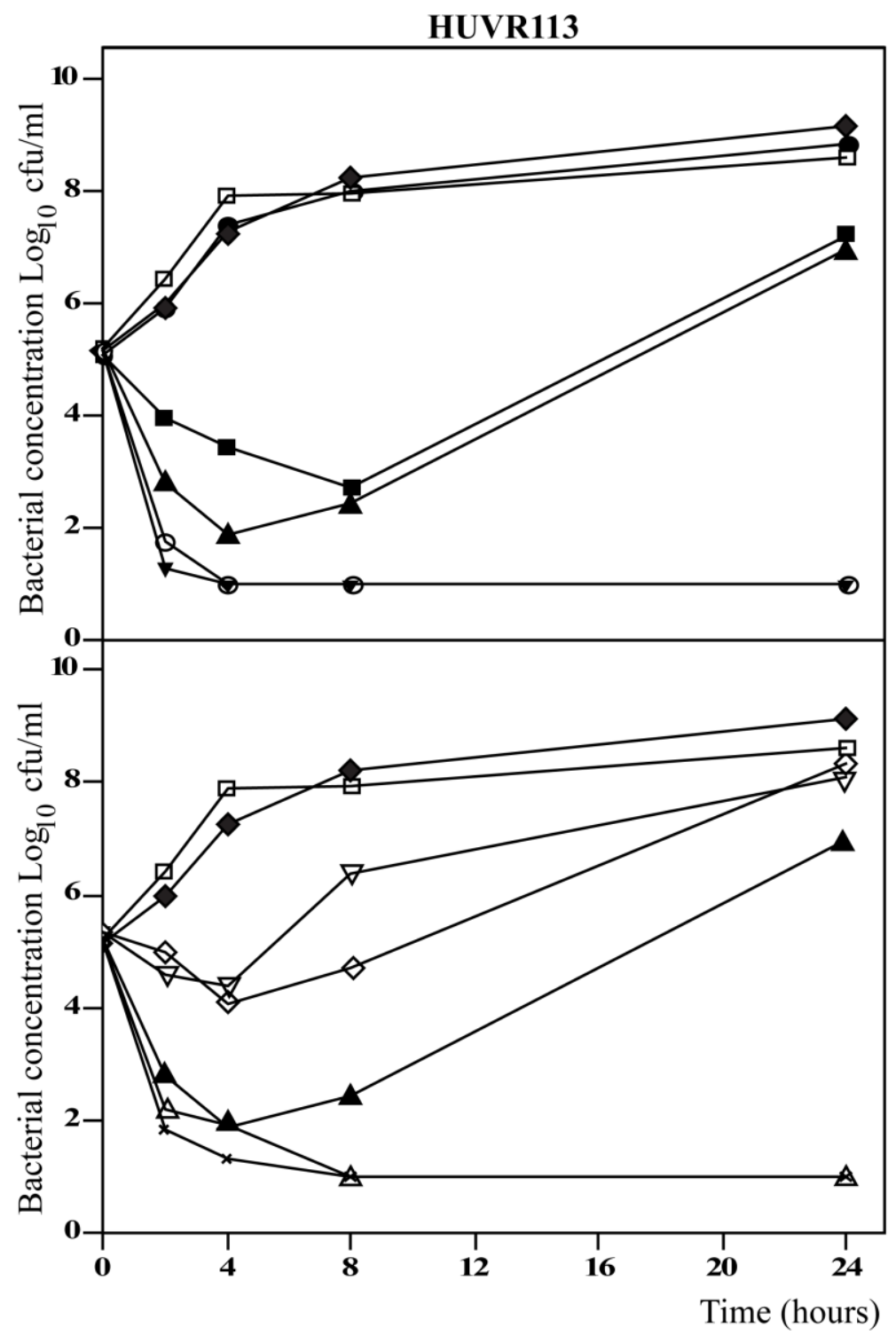

Figure 2, legend. Control, filled diamond; rifampin (MIC), filled triangle; rifampin $\left(C_{\max }\right)$,

434 open square; imipenem (MIC), filled square; imipenem $\left(C_{\max }\right)$, filled circle; sulbactam 435 (MIC) open inverted triangle; sulbactam $\left(C_{\max }\right)$, open diamond; rifampin plus imipenem 436 (MIC), open circle; rifampin plus imipenem $\left(C_{\max }\right)$, inverted filled triangle; rifampin plus 437 sulbactam (MIC), open triangle; rifampin plus sulbactam $\left(C_{\max }\right)$, black cross. 